\title{
CORRIGENDUM
}

\section{Integrins in cancer: biological implications and therapeutic opportunities}

Jay S. Desgrosellier \& David A. Cheresh

Nature Reviews Cancer 10, 9-22 (2010)

On page 17 of this article, in the section Targeting $\alpha v \beta 3$ and $\alpha v \beta 5$ the sentence at the start of the second paragraph that reads "Cilengitide is an inhibitor of both $\alpha v \beta 3$ and $\alpha v \beta 5$ integrins, and it was selected in our laboratory by screening a library of cyclic RGD peptides in a cell-free receptor assay for their capacity to inhibit integrins $\alpha v \beta 3$ and $\alpha v \beta 5$ but not $\alpha \operatorname{IIb} \beta 3$ (REF. 130)." was incorrectly phrased. The corrected sentence with additional references is given below.

"Cilengitide is an inhibitor of both $\alpha v \beta 3$ and $\alpha v \beta 5$ integrins. We had shown that $\alpha v \beta 3$ and $\alpha v \beta 5$ integrins were important regulators of angiogenesis and tumour growth ${ }^{49,51,191,192}$ and developed a cell-free receptor assay to select for antagonists of integrins $\alpha v \beta 3$ and $\alpha v \beta 5$ that did not effect integrin $\alpha I b \beta 3$ (REF. 130). This assay was used to screen a library of integrin binding cyclic RGD peptides designed and synthesized by H. Kessler and colleagues for $\alpha v \beta 3$ activity and selectivity ${ }^{193-195}$ from which cilengitide was developed ${ }^{196} "$.

191. Cheresh, D. A. Human endothelial cells synthesize and express an Arg Gly Asp-directed adhesion receptor involved in attachment to fibrinogen and von Willebrand factor. Proc. Natl. Acad. Sci. USA 84, 6471-6475 (1987)

192. Brooks, P. C. et al. Integrin $\alpha v \beta 3$ antagonists promote tumor regression by inducing apoptosis of angiogenic blood vessels. Cell 79, 1157-1164 (1994).

193. Aumailley, M. et al. Arg Gly Asp constrained within cyclic pentapeptides. Strong and selective inhibitors of cell adhesion to vitronectin and laminin fragment P1. FEBS Lett. 291, 50-54 (1991).

194 Gurrath, M et al. Conformation/activity studies of rationally designed potent anti-adhesive RGD peptides; Eur. $J$. Biochem., 210, 911-921 (1992)

195. Pfaff, M. et al., Selective Recognition of Cyclic RGD Peptides of NMR Defined Conformation by $\alpha$ llb $\beta 3, \alpha V \beta 3$ and $\alpha 5 \beta 1$ Integrins. J. Biol. Chem., 269, 20233-20238 (1994).

196. Dechantsreiter, M. A. et al. $N$-Methylated cyclic RGD peptides as highly active and selective $\alpha_{v} \beta_{3}$ integrin antagonists. J. Med. Chem. 42, 3033-3040 (1999). 